\title{
Retinal pigment epithelium, age-related macular degeneration and neurotrophic keratouveitis
}

\author{
ENRICA BIANCHI $^{1}$, FABIO SCARINCI ${ }^{2}$, GUIDO RIPANDELLI ${ }^{2}$, JANOS FEHER $^{1}$, ELENA PACELLA ${ }^{1}$, \\ GIUSEPPE MAGLIULO $^{1}$, CORRADO BALACCO GABRIELI ${ }^{1}$, ROCCO PLATEROTI ${ }^{1}$, \\ PASQUALE PLATEROTI ${ }^{1}$, FIORENZO MIGNINI ${ }^{3}$ and MARCO ARTICO ${ }^{1}$ \\ ${ }^{1}$ Department of Sensory Organs, University of Rome 'La Sapienza', Rome; ${ }^{2}$ Bietti Eye Foundation IRCCS, Rome; \\ ${ }^{3}$ School of Drug and Health Products Sciences, University of Camerino, Camerino, Italy
}

Received July 26, 2012; Accepted September 25, 2012

DOI: $10.3892 / \mathrm{ijmm} .2012 .1164$

\begin{abstract}
Age-related macular degeneration (AMD) is the leading cause of impaired vision and blindness in the aging population. The aims of our studies were to identify qualitative and quantitative alterations in mitochondria in human retinal pigment epithelium (RPE) from AMD patients and controls and to test the protective effects of pigment epithelium-derived factor (PEDF), a known neurotrophic and antiangiogenic substance, against neurotrophic keratouveitis. Histopathological alterations were studied by means of morphometry, light and electron microscopy. Unexpectedly, morphometric data showed that the RPE alterations noted in AMD may also develop in normal aging, 10-15 years later than appearing in AMD patients. Reduced tear secretion, corneal ulceration and leukocytic infiltration were found in capsaicin (CAP)-treated rats, but this effect was significantly attenuated by PEDF. These findings suggest that PEDF accelerated the recovery of tear secretion and also prevented neurotrophic keratouveitis and vitreoretinal inflammation. PEDF may have a clinical application in inflammatory and neovascular diseases of the eye.
\end{abstract}

\section{Introduction}

Age-related macular degeneration (AMD) is a progressive neurodegenerative disease of the central retinal area (macula lutea) and it represents the most common cause of legal blindness in industrialized countries $(1,2)$. Epidemiologic studies from several countries also showed a dramatic increase in the prevalence and severity of AMD with age. Despite intensive basic and clinical research, its pathogenesis remains unclear,

Correspondence to: Dr Enrica Bianchi, Department of Sensory Organs, University of Rome 'La Sapienza', Viale del Policlinico 155, 00161 Rome, Italy

E-mail: enrica.bianchi@uniroma1.it

Key words: retinal pigment epithelium, mitochondria, lipofuscin, peroxisomes, age-related macular degeneration, pigment epitheliumderived factor, light microscopy, electron microscopy, morphometry likely due to its multifactorial character (3-6). In addition to a strong age-dependence of the disease, a complex interaction of metabolic, functional, genetic and environmental factors appears to create a platform for chronically developing changes in the ocular structures of the macular region [choriocapillaries, Bruch's membrane, retinal pigment epithelium (RPE), photoreceptors] which may contribute in varying degrees to the onset of AMD.

Traditionally, two subgroups of AMD can be distinguished: atrophic (dry form) and exudative (wet form). The dry form, synonymously known as age-related maculopathy, is characterized by the presence of small yellowish deposits (drusen) under the RPE, accompanied with either loss or focal accumulation of melanin pigment. This form of AMD is typically characterized by a progressing course leading to degeneration of RPE and photoreceptors. The exudative form is linked to choroidal neovascularization directed to the subretinal macular region, with subsequent bleeding and/or fluid leakage, which may result in a sudden loss of central vision; it is the most rapidly progressing form of AMD. Both atrophic and exudative forms are associated with severe impairment of visual functions (7). The pathophysiology of AMD is complex and, in addition to genetic predispositions, at least 4 processes contribute to the disease: lipofuscinogenesis, drusogenesis, local inflammation and neovascularization (in the case of the wet form) (3-13). The current pathophysiologic concept regarding AMD assigns a primary role to the age-related, cumulative oxidative damage to the RPE due to an imbalance between generation and elimination of reactive oxygen species (ROS) (14-16). Specifically, lipofuscin, a heterogeneous material composed of a mixture of lipids (lipid peroxides, proteins and different fluorescent compounds derived mainly from vitamin A), has been hypothesized to be the primary source of ROS responsible for both cellular and extracellular matrix alterations in AMD (17-19).

Accumulation of lipofuscin, other lipid peroxides and potentially toxic substances may dramatically influence the RPE physiology. In vitro it greatly reduces the phagocytic capacity, lysosomal enzyme activities and antioxidant potential of human RPE $(20,21)$. In vivo studies support findings regarding the in vitro effects of lipofuscin on RPE metabolism (22). N-retinylidene-N-retinylethanolamine (A2E), the major 
autofluorescent component of lipofuscin, specifically targets cytochrome $c$ oxidase $(23,24)$, causes caspase activation and RPE cell apoptosis $(18,19)$. Thus, lipofuscin is thought to be responsible for oxidative damage to RPE resulting in impaired metabolism and apoptosis characteristic of late AMD (15).

Mitochondria play a central role in aging and in the pathogenesis of age-related neurodegenerative diseases (25). Early studies have revealed several abnormalities in mitochondrial DNA (mtDNA) and subsequent disorders of respiratory enzyme complexes accompanied by reduced energy production, generation of excessive ROS and activation of the apoptosis pathway (26). However, recent studies suggest that mitochondrial dysfunctions may also include compositional and structural alterations in mitochondrial membranes (mtMEM) (27,28). Alterations in membrane lipid composition, such as decreases in cardiolipin content or changes in the $\omega-3 / \omega-6$ ratio, impair the electron transport chain and energy production (29), ion channel and $\mathrm{Ca}^{2+}$ homeostasis of the mitochondria and of the cell (30-33). These alterations can also impair carnitine-mediated lipid transport, mitochondrial lipid metabolism (34,35), cholesterol biosynthesis (36-39), activity of the pyruvate dehydrogenase complex $(40,41)$ and, finally, cause activation of the apoptosis pathway (42). In the present study, detailed electron microscopy of human RPE cells from aged and AMD specimens are described. Based on morphometric data, we found that progressive deterioration of mtMEM with aging occurred in association with peroxisome proliferation and accumulation of lipofuscin in the RPE, and alterations in the RPE mtMEM and proliferation of peroxisomes were significantly more severe in AMD compared to normal aging.

Sensory innervation of the eye comes from the first branch of the trigeminal nerve and it plays an essential role in the physiology and pathophysiology of both the anterior and posterior segments of the eye $(43,44)$. Sensory nerves regulate tear secretion either through the sensory arc of reflex tearing (45) or directly through releasing neuropeptides from sensory nerve endings (46). Both mechanisms are involved in the development of dry eye syndromes $(47,48)$. Although the retina has no sensory innervations, substance P (SP)- and calcitonin gene-related peptide (CGRP)-containing amacrine and ganglion cells have been observed in the retina in various species including humans (49-51). Furthermore, several experimental studies have suggested that these neuropeptides are involved in various retinal diseases (52-54). Previously, an increase in SP and CGRP immunoreactivity was observed in the retina after electric stimulation of the trigeminal ganglion (55). However, the mechanism by which these neuropeptides are generated in the retina has yet to be elucidated. Capsaicin (CAP), a neurotoxic substance for polymodal C sensory nerve fibers, is widely used in experiments, either for sensory nerve stimulation or sensory nerve damage, depending on the dose applied (56). Animals exposed to CAP exhibit various corneal lesions, including a reduction in the number of corneal nerve fibers and disintegration of epithelial cells $(57,58)$. In addition, changes in the physiology of the ocular surface, such as a reduction in tear fluid secretion, impairment of corneal epithelial barrier function and a delay in corneal epithelial wound healing, are apparent in such animals (59). These CAP-induced changes thus appear to be similar to those characteristic of neurotrophic keratouveitis in humans (60). Degeneration of amacrine and ganglion cells has also been observed after CAP treatment (61). Pigment epitheliumderived factor (PEDF) has been isolated from the RPE and has also been found in the vitreous and the cornea (62). PEDF was originally identified as a neurotrophic factor (63). Subsequently, it was found to possess potent antiangiogenic activity $(64,65)$. It has been shown that PEDF is essential for maintaining the avascularity of the cornea and vitreous $(66,67)$ and that it influences CAP-induced neurotrophic keratouveitis. We confirm that retrobulbar administration of PEDF may attenuate the effect of CAP on tear secretion, keratouveitis and the retina.

\section{Materials and methods}

Sixty-five human eyes (age range 2-87 years) were selected for these electron microscopic studies. All experiments were conducted in accordance with the Declaration of Helsinki (1964) and with the understanding and consent of the human subjects. The responsible ethics committee approved the experiments. Three eyes, aged 2, 7 and 27 years, were used only for qualitative analysis of age-related changes. Thirty-one of the eyes were affected by early AMD (ages from 42 to 87 years, mean age 70.9 years; 20 female and 11 male) and 31 non-affected eyes were used for age- and gender-matched controls for both the qualitative and quantitative morphometric studies. The selection criteria for early AMD was based on the presence of drusen and/or basement membrane thickening of the RPE, while in the controls no drusen or basement membrane thickening of RPE was observed by electron microscopy. Late forms of AMD (geographic atrophy and/or choroidal neovascularization) were excluded from these studies. All of the human eyes had been surgically removed as a result of malignant tumors or severe ocular trauma, neither of which affected the posterior pole of the eyeball.

One hundred and forty-four 4-week-old Sprague-Dawley rats, weighing $\sim 200 \mathrm{~g}$ and of both sexes, maintained in standard laboratory conditions at $22^{\circ} \mathrm{C}$ temperature, $60 \%$ humidity and a 12-h light/dark cycle, were divided into 6 groups of 24 rats each. Care and treatment of the animals conformed to the ARVO Statement for the Use of Animals in Ophthalmic and Vision Research, avoiding animal suffering at each stage of the experiments. Rats of the first group (CAP) were given a single retrobulbar injection of CAP $50 \mathrm{mg} / \mathrm{kg}$ (Sigma-Aldrich, St. Louis, MO, USA) in a procedure described elsewhere. Rats in the second (CAP+PEDF 3.2 from Day 0) and third (CAP+PEDF 6.4 from 0) groups received the same injection of CAP plus daily retrobulbar injections of 3.2 or $6.4 \mu \mathrm{g} / \mathrm{kg}$ PEDF starting from Day 0 (BioProducts, Middletown, MD, USA), respectively. Rats in the fourth (CAP+PEDF 3.2 from Day 14) and fifth (CAP+PEDF 6.4 from Day 14) group also received the same CAP plus daily retrobulbar injection of 3.2 or $6.4 \mu \mathrm{g} / \mathrm{kg}$ PEDF starting at Day 14 after CAP challenge. The sixth (control) group (C) received the vehicle solution alone. One randomly selected eye of each rat was used and the untreated fellow eye was used to evaluate eventual systemic effects. PEDF treatment was repeated daily until the end of the study. 
Electron microscopy. Small pieces of the human retina and choroid were dissected at the posterior pole $<2$ min after removal of the eyeball and fixed at $4{ }^{\circ} \mathrm{C}$ in $2 \%$ buffered glutaraldehyde for $2 \mathrm{~h}$ and postfixed in $2 \%$ osmium tetroxide for another $2 \mathrm{~h}$. The postfixation with osmium tetroxide demonstrates lipid peroxides as effectively as tetramethylbenzidine but avoids incubation, which might damage membrane structures (68). The specimens were dehydrated, embedded in Araldite, sectioned with a Reichert ultramicrotome (Reichert, Vienna, Austria), contrasted with lead citrate and uranyl acetate and studied with a Zeiss 109 electron microscope.

Small pieces $(1 \times 1 \mathrm{~mm})$ of the rat cornea were dissected and fixed in buffered $2 \%$ glutaraldehyde for $2 \mathrm{~h}$, postfixed in $2 \%$ osmium tetroxide for another $2 \mathrm{~h}$, dehydrated and embedded in Araldite. Ultrathin sections were cut with an ultramicrotome (Reichert), contrasted with uranyl acetate and lead citrate and studied with an electron microscope. After prefixation, rat tissue samples were oriented and the exposed surface was coated with gold-carbon vapor and examined with an electron microscope equipped with a high-resolution scanning device used for photography (EM Asid JEM-100B; JEOL, Tokyo, Japan).

Light microscopy. Six rats from each group were sacrificed using carbon dioxide at Days 7, 14, 28 and 42. The eyes were enucleated and fixed in Karnovsky's solution for $48 \mathrm{~h}$, dehydrated and embedded in paraffin, and the 6- $\mu \mathrm{m}$ sections were colored with $H \& E$ and Masson's trichrome staining for light microscopy. In addition, myeloid leukocytes labeled with chloroacetate-esterase were counted in the H\&E-stained sections under light microscopy. Chloroacetate-esterase specifically identifies cells of the granulocyte lineage, from the early promyelocyte stage to mature neutrophils. The number of leukocytes was counted in the anterior chamber, posterior chamber, peripheral retina and peripheral vitreous at the same microscopic magnification.

Morphometry. In the parafoveal area of the macula, the total number of mitochondria, number of lipofuscin granules and number of peroxisomes were counted at a magnification of $x 8,000$. The number of well-defined mitochondrial cristae and the area of the mitochondria and lipofuscin, were measured in 6-8 RPE cells/specimen at a magnification of $x 20,000$. Each organelle was outlined and the area was determined using the NIH Image J program. Morphometric analysis was performed by two experienced observers, and the questionable cases were re-evaluated by the senior researcher.

Tear secretion. Tear fluid secretion was measured without topical anesthesia by a modified version of the Schirmer's test. Schirmer strips cut to dimensions of $20 \times 1 \mathrm{~mm}$ were inserted below the lower eyelid of the test animal for $1 \mathrm{~min}$. The wet length of the strip was measured to an accuracy of $\pm 0.5 \mathrm{~mm}$. The Schirmer's test was performed at Day 1 (before any treatment) and at Days 7, 14, 28 and 42 after CAP injection.

Statistical analysis. Data are expressed as means \pm SD and were analyzed using Statistica 6.0 software (StatSoft, Inc., Tulsa, OK, USA). In the first experimental model to measure the relation between age and the evaluated parameters, linear regression analysis was applied for determining the P-value and Pearson correlation coefficient, r. We used 2-sided comparisons to detect any difference between linear regression results of the aged and AMD groups. In all cases $\mathrm{P}<0.05$ was considered to indicate a statistically significant result.

In the second experimental model, statistical analysis was performed with repeated-measures ANOVA using the Dunnett's multiple-comparison test for results in the 3 groups. After Bonferroni adjustment, the significance level was set at $\mathrm{P}<0.01$.

\section{Results}

Concerning age-related changes of the RPE and Bruch's membrane, electron microscopy showed very marked differences between young and aged human specimens (Fig. 1A and B). Mitochondria in young RPE were numerous, mostly bacillus-like shaped and oriented parallel to the apical-basal axis (Fig. 1A). They were typically rich in wellpreserved cristae. In normal aged eyes, mitochondria of the RPE clearly decreased in number (Fig. 1B), were variable in size and were usually oval-shaped without any preferential orientation. In some instances, there was disorganization of cristae, ranging from focal to complete loss, in association with decreased electron density of the matrix. Mitochondria of the RPE in AMD eyes (Fig. 2B) appeared to decrease in number and size when compared to the normal aging eyes (Fig. 2A). They were often round or oval, with focal or even complete loss of cristae and associated with more extensive decreases in matrix density (Fig. 3). In some instances, either bleb formation or interruption of the mitochondrial internal and external membranes was observed. These may be considered pre-apoptotic alterations. All of these mitochondrial alterations were apparently more marked and more extensive in AMD compared to normal aging. Bruch's membrane fine structure was clearly visible in young eyes (Fig. 1A) and consisted of a core elastic layer, outer and inner collagenous layers, basement membranes of the RPE and choriocapillaries. During normal aging, there was an increase in electron density of Bruch's membrane (Fig. 1B). Moreover, both inner and outer collagenous layers contained electrondense granular and vesicular material. Bruch's membrane showed characteristic differences in AMD compared to normal aged eyes. In addition to the age-related increase in thickness and electron density of collagenous layers, AMD specimens usually showed multiplex, focal thickenings of the inner collagenous layer known as hard or soft drusen. Apart from drusen, thickenings of the RPE basement membrane due to basal laminar deposits were also present. In most cases they were focal, wart-like depositions of filamentous material in which several electron-dense areas, possibly composed of lipids, were present. Cytoplasmic processes of the RPE invading this excessive basement membrane material were frequently observed.

Peroxisomes in the RPE were 0.1-0.3 $\mu \mathrm{m}$ in diameter, smaller than that in other cells (Fig. 1A and B). Some of these peroxisomes had electron-dense cores while others had a granular appearance. They were usually localized in the basal region of the cytoplasm and occasionally next to the basal and basolateral cell membrane. In normal aged 


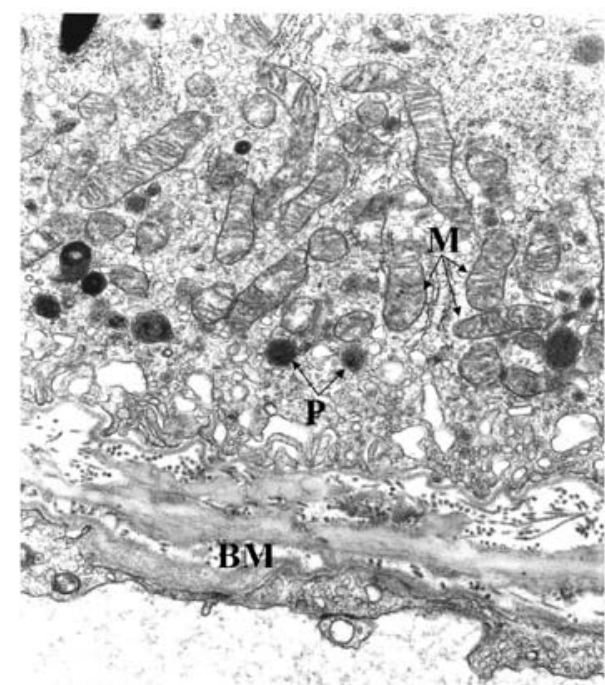

A

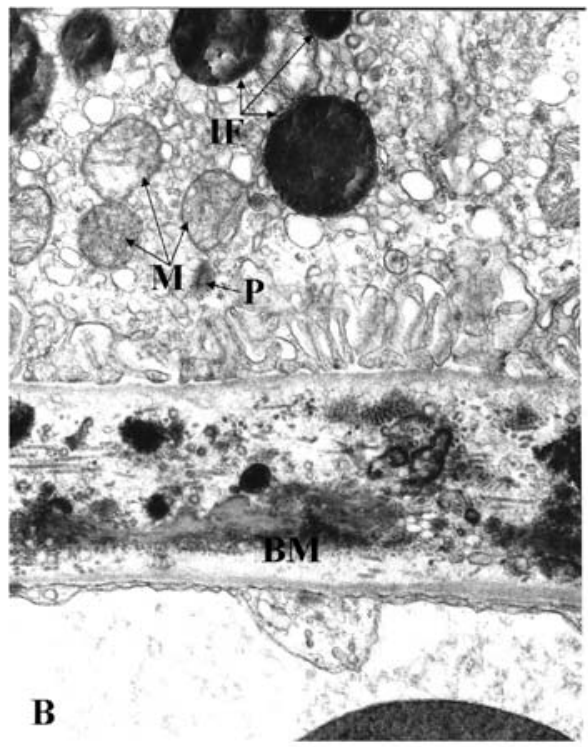

Figure 1. Representative electron micrographs of the RPE and Bruch's membrane. (A) Young RPE cells contained numerous bacillus-like mitochondria (M) with long axes oriented from the apical to the basal surfaces of the RPE. They were parallel to one another and closely packed, filling a large portion of the cytoplasm. The mitochondrial cristae were well preserved and the matrix was homogeneously electron-dense. The cytoplasm contained several rough-surface endoplasmic reticulum along with numerous small vesicles, probably microsomes. Several peroxisomes (P) appeared as small, round, electron-dense organelles. No lipofuscin granules were noted. There were numerous basal infoldings of the plasma membrane. Bruch's membrane (BM) ultrastructure was clearly visible and included an elastic core layer with some interruptions, inner and outer collagenous layers, basement membrane of the RPE and choriocapillaries. Two-year-old male; magnification, $x 25,000$ (B) Aged RPE cells had mitochondria (M) that showed various degrees of membrane disorganization. Mostly, there were focal losses of cristae accompanied by decreased electron density of the matrices. Numerous lipofuscin (IF) and melano-lipofuscin granules were present in the cytoplasm of the RPE. Peroxisomes (P) of various density, shape and size were distributed randomly in the cytoplasm of the RPE cells, even among the lipofuscin granules. Electron-dense homogeneous or granular material was present in Bruch's membrane (BM). Sixty-five-year-old female; magnification, x28,000.

eyes, peroxisomes were more numerous and more variable in size, electron-density and distribution than in young eyes. Furthermore, in young eyes they were dispersed
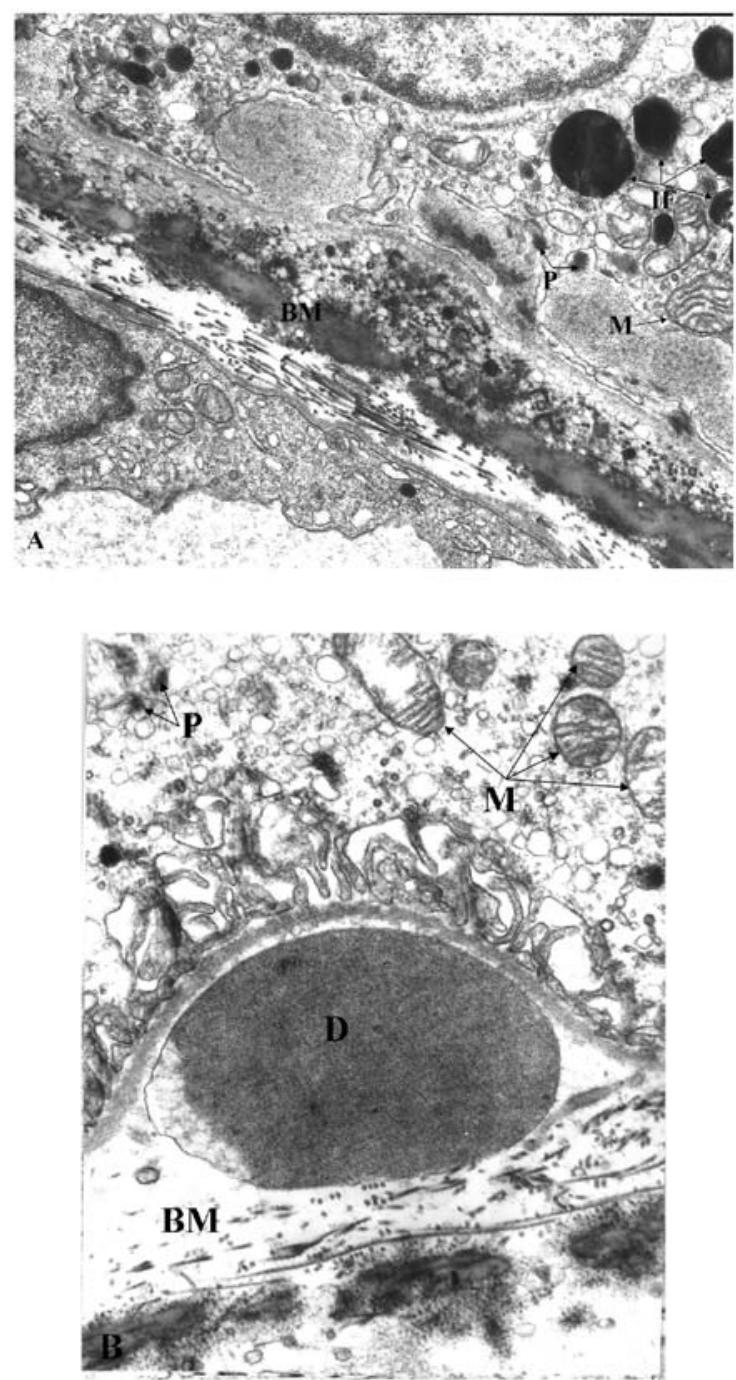

Figure 2. Comparison of the RPE in aged and AMD eyes. (A) In normal aging, most of the RPE mitochondria (M) had typical morphology, although several had focal loss of cristae and decreased electron density of the matrix. This micrograph also shows the thin basement membranes of the RPE and choriocapillaries, as well as interruptions of the elastic layer and deposition of amorphous materials in Bruch's membrane (BM). Some small round deposits were present in the collagenous layers of Bruch's membrane. Eightyfour-year-old female; The eye was removed due to malignant tumor, and the specimen came from the unaffected area; magnification, x26,000. (B) In AMD advanced mitochondrial alterations occurred in the RPE. Most mitochondria (M) had severe disorganization of membranes that varied from focal to complete loss of cristae and decreased electron density of the matrix. Several peroxisomes $(\mathrm{P})$ were randomly distributed in the basal cytoplasm of the RPE. Focal thickenings of the RPE basement membrane and a drusen (D) were also present in Bruch's membrane (BM). Several cytoplasmic processes protruded into the thickened basement membrane. Seventy-four-year-old female; the eye was removed due to a perforating injury; magnification, x32,000.

randomly in the cytoplasm of the RPE, while in aged eyes they formed small groups containing 4-5 peroxisomes. The distribution of peroxisomes in AMD eyes was highly variable within each RPE cell. Occasionally, they were located in the apical cytoplasm among the lipofuscin granules. More rarely, peroxisomes were in close topographic correlation with mitochondria and the nucleus of the RPE cells. In osmium-fixed specimens the peroxisomes varied in electron density. Lipofuscin granules and residual bodies were exceptionally rare at an early age, but they clearly increased 


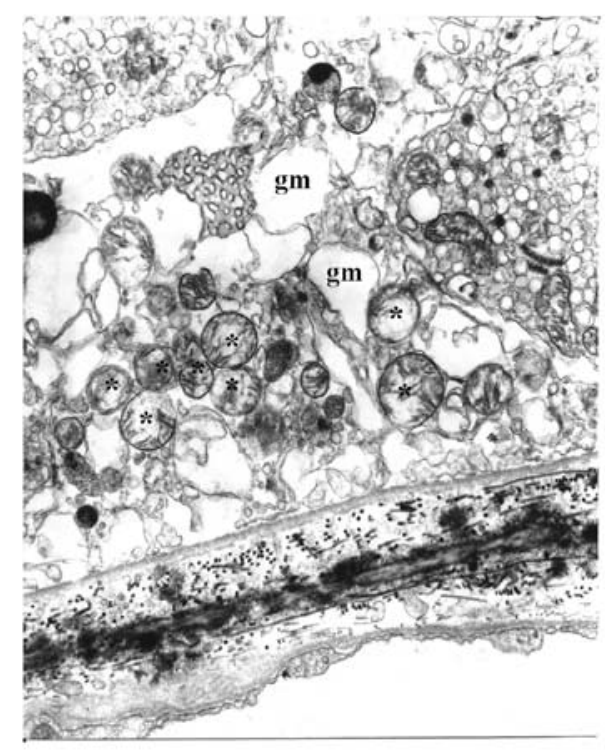

Figure 3. Representative electron micrograph of mitochondrial alterations in AMD. Extensive loss of cristae and matrix density occurred in most mitochondria (*). Several had complete loss of internal structure and appeared as 'ghost mitochondria' (gm). Some peroxisomes were adjacent to the mitochondria. Seventy-one-year-old female; magnification, x22,000.

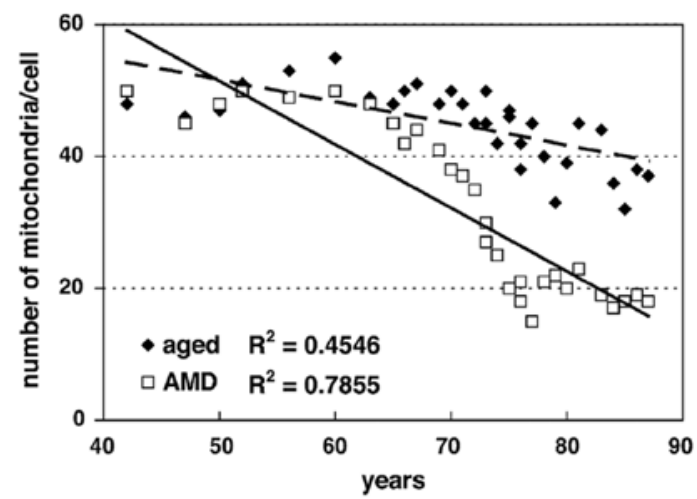

Figure 4. In both aged and AMD groups, there were significant decreases in the number of mitochondria with age $(\mathrm{P}<0.001)$. In addition, the rate of loss in the AMD group was significantly greater than that in the normal aging group $(\mathrm{P}=0.038)$.

in number and size with time (Fig. 1B). In aged adults they were abundantly distributed in the cytoplasm of the RPE. Numerous melanolipofuscin granules were also present, formed by fusion of melanosomes and lipofuscin. These organelles were located in the apical half of the RPE in normal aged eyes. Lipofuscin granules and residual bodies in AMD specimens presented a morphology and distribution similar to control eyes.

Morphometric analysis of the electron micrographs quantified the mitochondrial and peroxisomal alterations. The total number of mitochondria decreased significantly in both aged $\left(\mathrm{R}^{2}=0.455 ; \mathrm{P}<0.001\right)$ and AMD $\left(\mathrm{R}^{2}=0.778 ; \mathrm{P}<0.001\right)$ groups (Fig. 4). The decrease in the AMD group was more severe and the difference was statistically significant $(\mathrm{P}=0.038)$. The number of mitochondria at age 75 in the AMD group was equivalent to that at age 85 in the control group. These

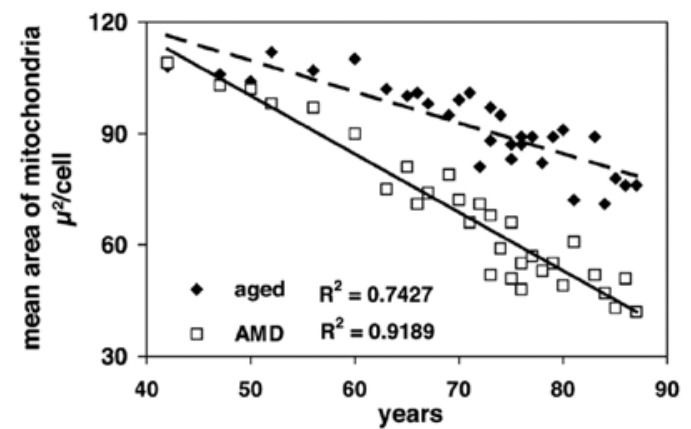

Figure 5. Both aged and AMD groups had significant decreases in the area of mitochondria with age $(\mathrm{P}<0.001)$. This decrease was significantly more marked in AMD patients compared to age-matched controls $(\mathrm{P}=0.019)$.

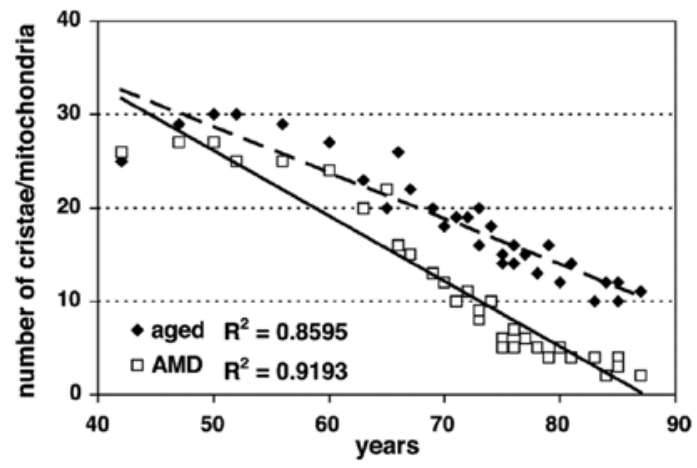

Figure 6. Changes in the number of mitochondrial cristae. Both aged and AMD mitochondria showed significant loss of cristae $(\mathrm{P}<0.001)$. Although the disorganization of mitochondrial cristae was more extensive in the AMD group compared to age-matched controls, the difference between them was not statistically significant $(\mathrm{P}=0.28)$.

findings suggest that with age the number of mitochondria decreased more rapidly in AMD compared to normal aged patients.

The area of the mitochondria also decreased significantly with age in both control $\left(\mathrm{R}^{2}=0.743 ; \mathrm{P}<0.001\right)$ and $\mathrm{AMD}$ $\left(\mathrm{R}^{2}=0.919 ; \mathrm{P}<0.001\right)$ groups (Fig. 5). The decrease in the AMD group was again more severe and the difference between the control and AMD groups was statistically significant $(\mathrm{P}=0.019)$. The area of mitochondria at 85 years in the control group was similar to that of 70 years in the AMD patients; the decrease in area of mitochondria developing 15 years earlier in the AMD patients.

The number of well-defined mitochondrial cristae was also counted and it showed a significant decrease in both the control $\left(\mathrm{R}^{2}=0.861 ; \mathrm{P}<0.001\right)$ and $\mathrm{AMD}\left(\mathrm{R}^{2}=0.918 ; \mathrm{P}<0.001\right)$ groups (Fig. 6). However, the difference between controls and AMD was not significant $(\mathrm{P}=0.28)$. Comparison of data from the control group at 85 years showed again that the same loss of well-defined mitochondrial cristae developed 15 years earlier in AMD. The area of reduced matrix density corresponded to the loss of cristae (data not shown). Morphometric analysis showed a significant increase in the number of peroxisomes in both the control $\left(\mathrm{R}^{2}=0.207 ; \mathrm{P}<0.001\right)$ and AMD $\left(\mathrm{R}^{2}=0.608 ; \mathrm{P}<0.001\right)$ groups (Fig. 7). Moreover, the difference between the controls and AMD was statistically 


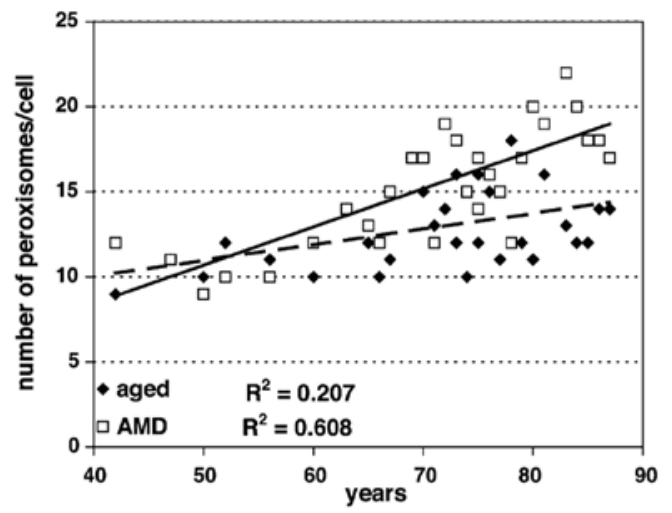

Figure 7. The number of peroxisomes increased with age in the aged $(\mathrm{P}<0.001)$ and AMD $(\mathrm{P}<0.001)$ groups. Furthermore, the increase was significantly greater in the AMD than in the age-matched controls $(\mathrm{P}=0.044)$.

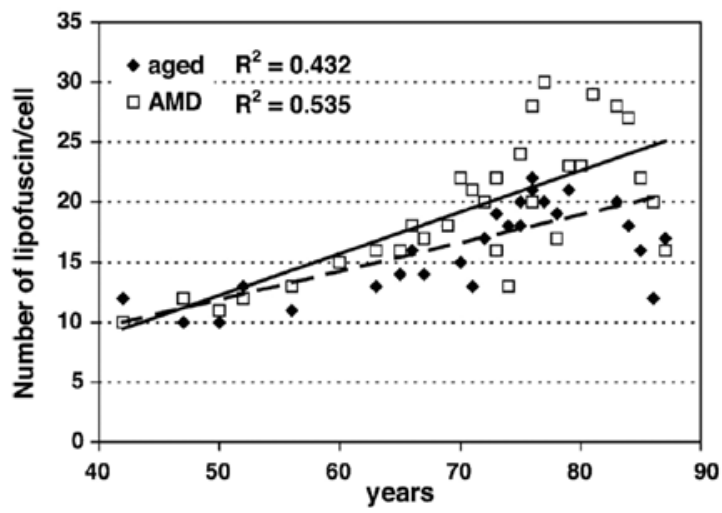

Figure 8 . The number of lipofuscin granules increased significantly with age in the aged $(\mathrm{P}=0.01)$ and $\mathrm{AMD}(\mathrm{P}<0.001)$ groups. The difference between the groups was not significant $(\mathrm{P}=0.61)$.

significant $(\mathrm{P}=0.044)$. Comparison of data from the normal aged group at 85 years showed the same levels $\sim 10$ years earlier in the AMD group. There was a significant increase in lipofuscin granules in both the control $\left(\mathrm{R}^{2}=0.432 ; \mathrm{P}<0.001\right)$ and AMD $\left(\mathrm{R}^{2}=0.535 ; \mathrm{P}<0.001\right)$ groups (Fig. 8). However, the difference between the two groups was not statistically significant $(\mathrm{P}=0.61)$. Comparison of data from the normal aged group at 85 years showed that the same increase in the number of lipofuscin granules developed $\sim 15$ years earlier in the AMD group. Our study did not reveal any substantial differences between females and males in both the aged and AMD groups.

In the second experimental model, we evaluated the tear fluid secretion by Schirmer's test in animals treated by retrobulbar injection of CAP and PEDF. CAP treatment resulted in a statistically significant decrease in tear secretion at Days 1

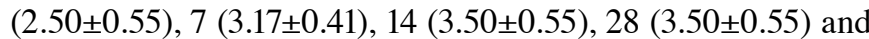
$42(3.67 \pm 0.52)$ compared with the control values $(6.83 \pm 1.33)$, $(6.50 \pm 1.38),(6.67 \pm 0.52),(6.67 \pm 0.52)$ and $(7.17 \pm 0.98)$, respectively. Treatment with 3.2 or $6.4 \mu \mathrm{g} / \mathrm{kg}$ PEDF from Day 0 attenuated the effect of CAP at Days 28 and 42 ( $\mathrm{P}<0.001)$ only, and a significantly decreased tear secretion was measured in group CAP+PEDF 3.2 at Days $1(2.67 \pm 0.52), 7(3.33 \pm 0.82)$, $14(4.17 \pm 0.75), 28(4.83 \pm 0.41)$ and $42(5.33 \pm 0.52)$ and in group

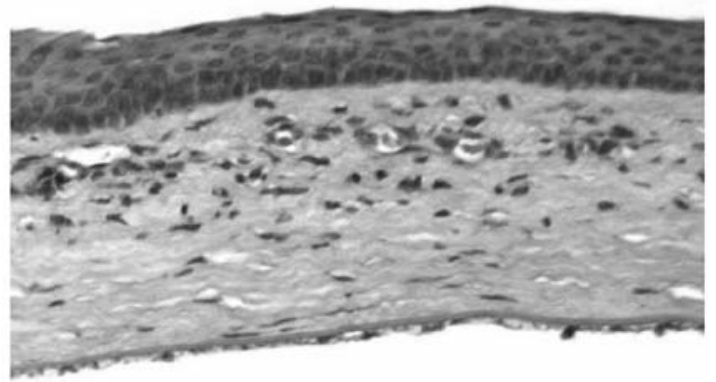

A

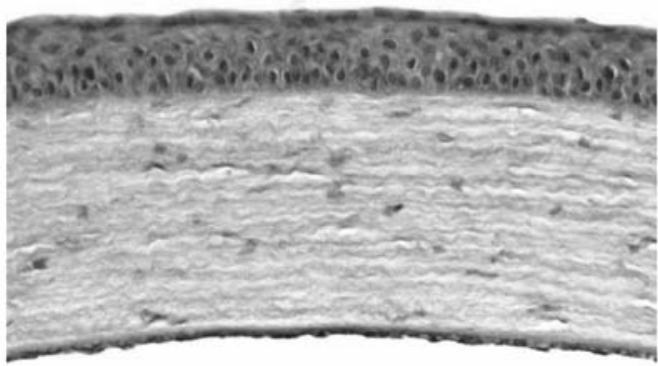

B

Figure 9. Light microscopy of CAP-induced keratouveitis. (A) H\&E staining. The cornea of the CAP-treated eye showed a thin and irregular epithelium, superficial scar tissue and neovascularization. Magnification, x200. (B) H\&E staining. The cornea of the CAP + PEDF 6.4 group had a normal appearance (Day 42). Magnification, x200.

CAP+PEDF 6.4 at Days $1(2.50 \pm 0.55), 7(3.83 \pm 0.41), 14$ $(4.33 \pm 0.52)$ and $28(5.33 \pm 0.52)$ compared with the controls. PEDF treatment initiated at Day 14 also attenuated the effect of CAP pretreatment on tear secretion, but these effects were not significant at any time point.

A single retrobulbar injection of CAP into young rats caused a clinically marked inflammation of the anterior segment progressing from slight punctate vacuolization in the epithelium at the second or third days to diffuse edematous opacities and neovascularization in the stroma, at the third or fourth week, persisting at least for 6 weeks. These alterations in the cornea showed continuous progression by the end of follow-up. In contrast, by administration of PEDF, both corneal opacities and scar formation were prevented and the cornea became completely transparent at the end of the treatment. The most prominent histopathologic feature of the affected corneas was a marked disorganization of the epithelium, followed by marked polymorphonuclear leukocyte influx as well as by edema and disorganization of the corneal stroma with degeneration and loss of the central epithelium. These alterations were accompanied by fibrinous and cellular exudation into the anterior chamber (Fig. 9A). Intercellular edema in the corneal epithelium was particularly evident, even in the basal and intermediate layers of the epithelium of CAP-treated animals. There was extensive corneal neovascularization occurring approximately on Day 14. Myeloid cell infiltration was also evident within the angle, the anterior chamber and the iris. Treatment with PEDF prevented and/ or significantly attenuated corneal epithelial and stromal damage in a dose-dependent manner (Fig. 9B). These data are provided in detail in Table I. 
Table I. Number of myeloid cells in the eyes at different time points of the study.

\begin{tabular}{|c|c|c|c|c|c|}
\hline Group & Localization & Day 7 & Day 14 & Day 28 & Day 42 \\
\hline \multirow[t]{4}{*}{ Control } & $\mathrm{AC}$ & $0.17 \pm 0.40$ & $0.33 \pm 0.51$ & $0.33 \pm 0.51$ & $0.5 \pm 0.55$ \\
\hline & $\mathrm{PC}$ & $0.16 \pm 0.41$ & $0.33 \pm 0.51$ & $0.33 \pm 0.51$ & $0.5 \pm 0.55$ \\
\hline & Vitreous & $0.16 \pm 0.41$ & $0.33 \pm 0.51$ & $0.33 \pm 0.51$ & $0.5 \pm 0.55$ \\
\hline & Retina & $0.16 \pm 0.41$ & $0.33 \pm 0.51$ & $0.33 \pm 0.51$ & $0.5 \pm 0.55$ \\
\hline \multirow[t]{4}{*}{ CAP-treated } & $\mathrm{AC}$ & $10.5 \pm 2.16^{\mathrm{a}}$ & $12.5 \pm 2.95^{\mathrm{a}}$ & $17.83 \pm 3.92^{\mathrm{a}}$ & $22.16 \pm 2.14^{\mathrm{a}}$ \\
\hline & $\mathrm{PC}$ & $9.17 \pm 0.75^{\mathrm{a}}$ & $12.5 \pm 1.38^{\mathrm{a}}$ & $17.83 \pm 1.72^{\mathrm{a}}$ & $21.5 \pm 2.07^{\mathrm{a}}$ \\
\hline & Vitreous & $2.66 \pm 0.52^{\mathrm{a}}$ & $4.67 \pm 1.21^{\mathrm{a}}$ & $7.67 \pm 0.82^{\mathrm{a}}$ & $9.33 \pm 1.75^{\mathrm{a}}$ \\
\hline & Retina & $5.83 \pm 1.47^{\mathrm{a}}$ & $9.83 \pm 2.14^{\mathrm{a}}$ & $15 \pm 2.61^{\mathrm{a}}$ & $19 \pm 2.83^{\mathrm{a}}$ \\
\hline \multirow{4}{*}{$\begin{array}{l}\text { CAP }+3.2 \mu \mathrm{g} \text { PEDF } \\
\text { from Day } 0\end{array}$} & $\mathrm{AC}$ & $7 \pm 0.89^{\mathrm{a}, \mathrm{b}}$ & $9 \pm 0.89^{\mathrm{a}, \mathrm{b}}$ & $5.83 \pm 1.16^{\mathrm{a}, \mathrm{b}}$ & $5.16 \pm 0.75^{\mathrm{a}, \mathrm{b}}$ \\
\hline & PC & $6.5 \pm .05^{\mathrm{a}, \mathrm{b}}$ & $7.67 \pm 0.82^{\mathrm{a}, \mathrm{b}}$ & $5.5 \pm 0.83^{\mathrm{a}, \mathrm{b}}$ & $4.5 \pm 0.55^{\mathrm{a}, \mathrm{b}}$ \\
\hline & Vitreous & $2.5 \pm 0.55^{\mathrm{a}}$ & $2.83 \pm 0.41^{\mathrm{a}, \mathrm{b}}$ & $3.5 \pm 1.22^{\mathrm{a}, \mathrm{b}}$ & $1.83 \pm 0.41^{\mathrm{b}}$ \\
\hline & Retina & $3 \pm 0.63^{a, b}$ & $3.67 \pm 1.03^{\mathrm{a}, \mathrm{b}}$ & $4.33 \pm 0.82^{\mathrm{a}, \mathrm{b}}$ & $2.67 \pm 1.03^{\mathrm{b}}$ \\
\hline \multirow{4}{*}{$\begin{array}{l}\text { CAP+6.4 } \mu \mathrm{g} \text { PEDF } \\
\text { from Day } 0\end{array}$} & $\mathrm{AC}$ & $3.83 \pm 0.41^{\mathrm{a}, \mathrm{b}}$ & $4.33 \pm 0.52^{\mathrm{a}, \mathrm{b}}$ & $4.16 \pm 1.47^{\mathrm{a}, \mathrm{b}}$ & $2.33 \pm 1.51^{\mathrm{b}}$ \\
\hline & $\mathrm{PC}$ & $3.83 \pm 0.41^{\mathrm{a}, \mathrm{b}}$ & $3.83 \pm 0.75^{\mathrm{a}, \mathrm{b}}$ & $3.5 \pm 0.83^{\mathrm{a}, \mathrm{b}}$ & $2 \pm 1.26^{\mathrm{b}}$ \\
\hline & Vitreous & $1.66 \pm 0.82^{\mathrm{a}}$ & $2.66 \pm 0.52^{\mathrm{a}, \mathrm{b}}$ & $2 \pm 1.26^{\mathrm{b}}$ & $0.33 \pm 0.52^{b}$ \\
\hline & Retina & $3.67 \pm 0.52^{\mathrm{a}, \mathrm{b}}$ & $2.67 \pm 0.51^{\mathrm{a}, \mathrm{b}}$ & $2.5 \pm 1.04^{\mathrm{b}}$ & $1 \pm 0.89^{b}$ \\
\hline \multirow{4}{*}{$\begin{array}{l}\mathrm{CAP}+3.2 \mu \mathrm{g} \text { PEDF } \\
\text { from Day } 14\end{array}$} & $\mathrm{AC}$ & $10.5 \pm 0.89^{\mathrm{a}}$ & $12.8 \pm 0.89^{\mathrm{a}}$ & $11.4 \pm 0.89^{\mathrm{a}, \mathrm{b}}$ & $10.0 \pm 0.89^{\mathrm{a}, \mathrm{b}}$ \\
\hline & $\mathrm{PC}$ & $9.8 \pm 1.03^{\mathrm{a}}$ & $12.6 \pm 0.98^{\mathrm{a}}$ & $12 \pm 0.89^{\mathrm{a}, \mathrm{b}}$ & $10.3 \pm 0.83^{\mathrm{a}, \mathrm{b}}$ \\
\hline & Vitreous & $3.1 \pm 0.75^{\mathrm{a}}$ & $5.3 \pm 0.83^{\mathrm{a}}$ & $5 \pm 0.83^{\mathrm{a}, \mathrm{b}}$ & $4.8 \pm 0.89^{\mathrm{a}, \mathrm{b}}$ \\
\hline & Retina & $6.8 \pm 0.89^{\mathrm{a}}$ & $10.6 \pm 0.89^{\mathrm{a}}$ & $9.4 \pm 0.98^{\mathrm{a}, \mathrm{b}}$ & $8.5 \pm 0.98^{\mathrm{a}, \mathrm{b}}$ \\
\hline \multirow{4}{*}{$\begin{array}{l}\text { CAP+6.4 } \mu \mathrm{g} \text { PEDF } \\
\text { from Day } 14\end{array}$} & $\mathrm{AC}$ & $11 \pm 0.98^{\mathrm{a}}$ & $13.1 \pm 0.89^{\mathrm{a}}$ & $11.6 \pm 0.89^{\mathrm{a}, \mathrm{b}}$ & $9.7 \pm 0.89^{\mathrm{a}, \mathrm{b}}$ \\
\hline & $\mathrm{PC}$ & $9.9 \pm 0.89^{a}$ & $12.4 \pm 1.14^{\mathrm{a}}$ & $11.8 \pm 0.89^{\mathrm{a}, \mathrm{b}}$ & $9.3 \pm 0.82^{\mathrm{a}, \mathrm{b}}$ \\
\hline & Vitreous & $4 \pm 0.83^{\mathrm{a}}$ & $6.0 \pm 0.82^{\mathrm{a}}$ & $5.1 \pm 0.75^{\mathrm{a}, \mathrm{b}}$ & $4.3 \pm 0.83^{\mathrm{a}, \mathrm{b}}$ \\
\hline & Retina & $7.2 \pm 0.89^{\mathrm{a}}$ & $11.2 \pm 0.89^{\mathrm{a}}$ & $9.7 \pm 0.98^{\mathrm{a}, \mathrm{b}}$ & $7.6 \pm 0.89^{\mathrm{a}, \mathrm{b}}$ \\
\hline
\end{tabular}

$\mathrm{AC}$, anterior chamber; $\mathrm{PC}$, posterior chamber; ${ }^{\mathrm{a}} \mathrm{P}<0.001$ compared with the control group; ${ }^{\mathrm{b}} \mathrm{P}<0.001$ compared with the $\mathrm{CAP}$ group at the given time point.

\section{Discussion}

Our electron microscopic study demostrated that mitochondria of the RPE undergo significant morphological changes with age as a result of marked decreases in the number and area of mitochondria, significantly more severe in ADM compared to age-matched controls. These changes include a partial to complete loss of cristae and decrease in the density of the mitochondrial matrix in both normal aging and AMD groups. To our knowledge, this is the first study to demonstrate alterations in mtMEM related to age and AMD in human RPE. It also revealed significant differences between normal aging and AMD. Ultrastructural and morphometric studies showed similar alterations in mtMEM in certain age-related human diseases, such as Alzheimer's disease (69), in the skeletal muscle of patients affected by type 2 diabetes or obesity (70) and in heart failure with chronic obstructive pulmonary disease (71), as well as in schizophrenia (72). Our findings suggest that RPE in aging and AMD should be included in that list. These data provide morphological support to the concept that mtMEM and subsequent mitochondrial dysfunctions may play a crucial role in the development of retinal degeneration, in particular of AMD $(16,73)$. Our data suggest that loss of mitochondrial structure is one of the differences between normal aging and AMD. Photoreceptors and RPE have an intimate morphologic and functional partnership in order to maintain adequate metabolic support for survival, excitability and turnover of photoreceptor cells. Mitochondrial $\beta$-oxidation, which is present in the RPE (74), is considered to be the major pathway that metabolizes fatty acids as a primary source of energy production $(75,76)$. Since the RPE is involved in the light-induced retinoid cycle $(77,78)$, one of the possible consequences of mitochondrial dysfunction in AMD may manifest as a disorder of light-induced retinoid recycle. Mitochondrial alterations were also accompanied by proliferation of peroxisomes. The morphometrical study showed that an age-related increase in peroxisome number in AMD specimens was significantly greater than the number in age-matched controls. Peroxisomes are membrane-bound organelles that play an essential role in lipid metabolism. They shorten the very-long-chain fatty acids, and the resulting long-chain fatty acids preferentially move back to the endoplasmic reticulum where they are used for membrane lipid synthesis (79), or they are then handed over to mitochondria for completion of oxidation (80). Intracellular elevation of naturally occurring fatty acids and eicosanoids activates 
peroxisome-proliferator-activated receptors (PPARs) resulting in peroxisome proliferation and activation of lipid metabolism (81). Activation of PPAR- $\alpha$ upregulates genes of lipid catabolism, while activation of PPAR $-\gamma$ upregulates genes of lipogenesis $(82,83)$. In a previous study $(84)$, PPAR- $\gamma$ ligands inhibited vascular endothelial growth factor-induced choroidal angiogenesis in vitro and choroidal neovascularization in vivo. This suggests the potential involvement of PPAR- $\gamma$ in AMD, at least in the development of the late form of this disease. The increased number of peroxisomes in aging and AMD may be a morphologic manifestation for activation of an alternative pathway for lipid degradation. This hypothesis is supported by observations that induction of PPAR- $\alpha$ was associated with a strong stimulation of the enzymes involved in peroxisomal $\beta$-oxidation $(85,86)$. However, only PPRA- $\gamma$ has been detected in human RPE (84). Accumulation of partially metabolized lipids such as lipofuscin and lipid peroxides in RPE may be another possible consequence of mitochondrial dysfunction $(20,87)$. Lipofuscin may be responsible for oxidative damage to the RPE that results in impaired metabolism and apoptosis characteristic of late AMD (15). Studies suggest that lipofuscin is a manifestation of the balance between production and elimination of partially metabolized substances, mostly lipid peroxide-containing materials $(88,89)$. Thus, the agerelated accumulation of intracellular lipofuscin is an indicator for impairment of lipid degradation processes (90). A previous autofluorescent study (91) showed a higher lipofuscin content in AMD compared to age-matched controls. Lipofuscin and other metabolized lipids containing ROS may certainly compromise RPE functions. However, the exact role of lipofuscin in AMD remains to be elucidated. Alterations in mtMEM influence the carnitine system located in the mitochondrial outer and inner membrane resulting in impaired lipid metabolism (35). mtMEM play an essential role in cholesterol metabolism in the liver and in several extrahepatic cells including macrophages (38), which have several features in common with RPE. A peripheral type benzodiazepine receptor, a channel-forming mitochondrial protein, is involved in the regulation of cholesterol transport from the outer to the inner mtMEM. This is the rate-determining step in steroid biosynthesis. The lipid composition of mtMEM might be involved directly in ion channel regulation (31). A decrease in mtMEM potential occurs in a variety of aging cell types from several mammalian species $(32,33)$. When mitochondria are subjected to oxidative stress and relatively high $\mathrm{Ca}^{2+}$, they may undergo a permeability transition in which the inner membrane becomes freely permeable to low-molecular-weight substances resulting in impairment of all mitochondrial functions (30). Mitochondrial ion channels are critically involved in apoptotic changes in mitochondria (42). In addition to the well-documented changes in mtDNA, our data suggest that alterations in mtMEM also play a crucial role in the development of mitochondrial dysfunctions in AMD and, possibly, in other age-related diseases (92). This has an immediate clinical relevance as shown by several in vitro and in vivo studies. In fact, mtMEM could be a target for treatment of mitochondrial dysfunctions. In vitro modification of mtMEM composition by $\omega-3$ fatty acids and addition of carnitine or acetyl-L-carnitine resulted in a subsequent improvement in mitochondrial lipid metabolism (93). An in vivo study showed that dietary $\omega-3$ fatty acids directly increase membrane $\omega-3 / \omega-6$ ratio, restore mtMEM cardiolipin content and membrane potential, as well as subsequently restore alterated mitochondrial $\mathrm{Ca}^{2+}$ flux and $\mathrm{Ca}^{2+}$-dependent processes such as activity of pyruvate dehydrogenase complex (94).

Furthermore, research demonstrated that a retrobulbar injection of CAP into young rats resulted in decreased tear secretion and neurotrophic keratouveitis characterized by epithelial alteration, stromal edema and scar formation accompanied by neovascularization of the cornea (60). In contrast to this study, we observed leukocyte infiltration in the posterior chamber, peripheral retina and vitreous body. These CAP-induced alterations were attenuated in a dose-dependent manner by retrobulbar injection of PEDF. CAP exerts its effects through binding to transient receptor potential vanilloid type 1 (TRPV1), which is a $\mathrm{Ca}^{2+}$-permeable ion channel. CAP may act on TRPV1 receptors of non-neuronal cells or sensory nerves of the cornea, conjunctiva, lacrimal glands, ciliary body and choroids. The activation of TRPV1 in the sensory nerve endings induces the release of the proinflammatory neuropeptides SP and CGRP, resulting in neurogenic inflammation, that may have been a leading contributing factor to the CAP-induced keratouveitis in our model. Non-neuronal cells include epithelial cells (keratinocytes, urothelium, gastric epithelial cells, enterocytes and pneumocytes), vascular endothelium and cells of the immune system as well as smooth muscle cells, fibroblasts and hepatocytes (95). PEDF accelerated the recovery of tear secretion and prevented neurotrophic keratouveitis and peripheral vitreoretinal inflammation by neurotrophic and antiangiogenic mechanisms. In vitro studies have shown that neuronal growth factors exert their effects through modulating TRPV1 expression and activity of sensory nerve cells (96). Recently, topical treatment with nerve growth factor (NGF) was also shown to restore corneal integrity in humans with corneal neurotrophic ulcers or keratitis (97). Moreover, there is accumulating evidence that in normal conditions there may be a balance between the release of PEDF and vascular endothelial growth factor (VEGF) (98). A decrease in the levels of PEDF or an increase in VEGF may be responsible for neovascularization in the exudative form of age-related macular degeneration (AMD), diabetic retinopathy and ischemia-induced retinal neovascularization (99). These findings suggest a certain antagonism between PEDF and VEGF (98). Contoversial studies have shown direct neurotrophic effects of VEGF similar to nerve growth factors suggesting a synergy between them in providing neuroprotection (100-102). Further studies are certainly needed to reveal the molecular mechanism of the association between PEDF and VEGF in both neuroprotection and angiogenesis.

In conclusion, our study on restoration of mitochondrial function are certainly very promising as they open up a new therapeutic approach to AMD. However, the correlation between mitochondrial dysfunction and Bruch's membrane alterations remains to be elucidated through ongoing studies. Clinical studies confirmed that a combination of acetyl-Lcarnitine, $\omega-3$ fatty acids and Coenzyme Q10, after an initial improvement, stabilized several visual functions in early AMD (103). However, further studies are also necessary to reveal how the clinically known risk factors of AMD are 
different between normal aging and AMD and why alterations of the RPE common to both normal aging and AMD groups occur at a younger age in AMD. This is also the first experimental study to suggest a neuroprotective and antiangiogenic effect of PEDF in CAP-induced keratouveitis. Although the involvement of TRPV1 is presumed, the molecular mechanisms of PEDF remain to be elucidated. PEDF is certainly related to neuroprotection and angiogenesis, but its role in the pathophysiology of the ocular compartment remains somewhat unclear.

\section{Acknowledgements}

The authors are very grateful to Ida Bozso for the technical assistance in preparing the microscopy specimens and to Sharon Hobby for the English language editing.

\section{References}

1. Friedman DS, O'Colmain BJ, Munoz B, Tomany SC, McCarty C, de Jong PT, Nemesure B, Mitchell P and Kempen J: Eye Diseases Prevalence Research Group. Prevalence of age-related macular degeneration in the United States. Arch Ophthalmol 122: 564-572, 2004

2. Klaver CC, Wolfs RC, Vingerling JR, Ofman A and De Jong PT: Age specific prevalence and causes of blindness and visual impairment in an older population: the Rotterdam Study. Arch Ophthalmol 116: 653-658, 1998.

3. Fine SL, Berger JW, Maguire MG and Ho AC: Age-related macular degeneration. N Engl J Med 342: 483-492, 2000.

4. McConnell V and Silvestri G: Age-related macular degeneration. Ulster Med J 74: 82-92, 2005.

5. Nowak JZ: Role of lipofuscin in pathogenesis of age-related macular degeneration (AMD). Mag Okul 2: 103-114, 2005 (In Polish).

6. Nowak JZ: Drusen, basal deposits, inflammation and age-related macular degeneration (AMD). Mag Okul 2: 174-186, 2005 (In Polish).

7. Bird AC, Bressler NM, Bressler SB, Chisholm IH, Coscas G, Davis MD, de Jong PT, Klaver CC, Klein BE, Klein R, et al: An international classification and grading system for agerelated maculopathy and age-related macular degeneration. The International ARM Epidemiological Study Group. Surv Ophthalmol 39: 367-374, 1995.

8. Anderson DH, Mullins RF, Hageman GS and Johnson LV: A role for local inflammation in the formation of drusen in the aging eye. Am J Ophthalmol 134: 411-431, 2002.

9. Campochiaro PA: Ocular neovascularization and excessive vascular permeability. Expert Opin Biol Ther 4: 1395-1402, 2004.

10. Kijlstra A, La Heij EC and Hendrikse F: Immunological factors in the pathogenesis and treatment of age-related macular degeneration. Ocular Immunol Inflam 13: 3-11, 2005.

11. Klein R, Peto T, Bird A and Vannewkirk MR: The epidemiology of age-related macular degeneration. Am J Ophthalmol 137: 486-495, 2004

12. Sparrow JR and Boulton M: RPE lipofuscin and its role in retinal pathobiology. Exp Eye Res 80: 595-606, 2005.

13. Wiktorowska-Owczarek A and Nowak JZ: Oxidative damage in age-related macular degeneration (AMD) and antioxidant protection as a therapeutic strategy. Pol J Environ Stud 15: 69-72, 2006.

14. Beatty S, Koh H, Phil M, Henson D and Boulton M: The role of oxidative stress in the pathogenesis of age-related macular degeneration. Surv Ophthalmol 45: 115-134, 2000.

15. Dunaief JL, Dentchev T, Ying GS and Milam AH: The role of apoptosis in age-related macular degeneration. Arch Ophthalmol 120: 1435-1442, 2002.

16. Winkler BS, Boulton ME, Gottsch JD and Sternberg P: Oxidative damage and age-related macular degeneration. Mol Vis 5: 32, 1999.

17. Hollyfield JG, Salomon RG and Crabb JW: Proteomic approaches to understanding age-related macular degeneration. Adv Exp Med Biol 533: 83-89, 2003.
18. Jin GF, Hurst JS and Godley BF: Rod outer segments mediate mitochondrial DNA damage and apoptosis in human retinal pigment epithelium. Curr Eye Res 23: 11-19, 2001.

19. Wolf G: Lipofuscin and macular degeneration. Nutr Rev 61: 342-346, 2003

20. Shamsi FA and Boulton M: Inhibition of the RPE lysosomal and antioxidant activity by the age pigment lipofuscin. Invest Ophthalmol Vis Sci 42: 3041-3046, 2001.

21. Sundelin S, Wihlmark U, Nilsson SE and Brunk UT: Lipofuscin accumulation in cultured retinal pigment epithelial cells reduces their phagocytic capacity. Curr Eye Res 17: 851-857, 1998.

22. Rakoczy PE, Zhang D, Robertson T, Barnett NL, Papadimitriou J, Constable IJ and Lai CM: Progressive age-related changes similar to age-related macular degeneration in a transgenic mouse model. Am J Pathol 161: 1515-1524, 2002.

23. Shaban H, Borras C, Vina J and Richter C: Phosphatidylglycerol potently protects human retinal pigment epithelial cells against apoptosis induced by A2E, a compound suspected to cause age-related macula degeneration. Exp Eye Res 75: 99-108, 2002.

24. Suter M, Remé C, Grimm C, Wenzel A, Jaattela M, Esser P, Kociok N, Leist M and Richter C: Age-related macular degeneration. The lipofusion component N-retinyl-N-retinylidene ethanolamine detaches proapoptotic proteins from mitochondria and induces apoptosis in mammalian retinal pigment epithelial cells. J Biol Chem 275: 39625-39630, 2000.

25. Kroemer G and Reed JC: Mitochondrial control of cell death. Nat Med 6: 513-519, 2000.

26. Schon EA and Manfredi G: Neuronal degeneration and mitochondrial dysfunction. J Clin Invest 111: 303-312, 2003.

27. James AM and Murphy MP: How mitochondrial damage affects cell function. J Biomed Sci 9: 475-487, 2002.

28. Toescu EC, Myronova N and Verkhratsky A: Age-related structural and functional changes of brain mitochondria. Cell Calcium 28: 329-338, 2000

29. Paradies G, Ruggiero FM, Petrosillo G and Quagliariello E: Age-dependent decline in the cytochrome $c$ oxidase activity in rat heart mitochondria: role of cardiolipin. FEBS Lett 406: 136-138, 1997.

30. Crompton M: Mitochondria and aging: a role for the permeability transition. Aging Cell 3: 3-6, 2004.

31. Gabbita SP, Subramaniam R, Allouch F, Carney JM and Butterfield DA: Effects of mitochondrial respiratory stimulation on membrane lipids and proteins: an electron paramagnetic resonance investigation. Biochim Biophys Acta 1372: 163-173, 1998.

32. Rottenberg $\mathrm{H}$ and Wu S: Mitochondrial dysfunction in lymphocytes from old mice: enhanced activation of the permeability transition. Biochem Biophys Res Commun 240: 68-74, 1997.

33. Sugrue MM and Tatton WG: Mitochondrial membrane potential in aging cells. Biol Signals Recept 10: 176-188, 2001.

34. Battelli D, Bellei M, Arrigoni-Martelli E, Muscatello U and Bobyleva V: Interaction of carnitine with mitochondrial cardiolipin. Biochim Biophys Acta 1117: 33-36, 1992.

35. Zammit VA, Corstorphine CG, Kolodziej MP and Fraser F: Lipid molecular order in liver mitochondrial outer membranes, and sensitivity of carnitine palmitoyltransferase I to malonylCoA. Lipids 33: 371-376, 1998.

36. Beaumont K, Skowronski R, Vaughn DA and Fanestil DD: Interactions of lipids with peripheral-type benzodiazepine receptors. Biochem Pharmacol 37: 1009-1014, 1988.

37. Campbell AM, Capuano A and Chan SH: A cholesterol-binding and transporting protein from rat liver mitochondria. Biochim Biophys Acta 1567: 123-132, 2002.

38. Hansson M, Ellis E, Hunt MC, Schmitz G and Babiker A: Marked induction of sterol 27-hydroxylase activity and mRNA levels during differentiation of human cultured monocytes into macrophages. Biochim Biophys Acta 1593: 283-289, 2003.

39. Papadopoulos V: Peripheral benzodiazepine receptor: structure and function in health and disease. Ann Pharm Fr 61: 30-50, 2003.

40. Denton RM, Randle PJ, Bridges BJ, Cooper RH, Kerbey AL, Pask HT, Severson DL, Stansbie D and Whitehouse S: Regulation of mammalian pyruvate dehydrogenase. Mol Cell Biochem 9: 27-53, 1975.

41. Robison WG Jr and Kuwabara T: Microperoxisomes in the retinal pigment epithelium. Invest Ophthalmol 14: 866-872, 1975.

42. Szabo II, Adams C and Gulbins E: Ion channels and membrane rafts in apoptosis. Pflugers Arch 448: 304-312, 2004. 
43. Beuerman RW and Stern ME: Neurogenic inflammation: a first line of defense for the ocular surface. Ocul Surf 3 (Suppl 4): S203-S206, 2005.

44. Troger J, Kieselbach G, Teuchner B, Kralinger M, Nguyen QA, Haas G, Yayan J, Gottinger W and Schmid E: Peptidergic nerves in the eye, their source and potential pathophysiological relevance. Brain Res Rev 53: 39-62, 2007.

45. Stern ME, Gao J, Siemasko KF, Beuerman RW and Pflugfelder SC: The role of the lacrimal functional unit in the pathophysiology of dry eye. Exp Eye Res 78: 409-416, 2004.

46. Kovacs I, Ludany A, Koszegi T, Fehér J, Kovacs B, Szolcsanyi J and Pintér E: Substance P released from sensory nerve endings influences tear secretion and goblet cell function in the rat. Neuropeptides 39: 395-402, 2005.

47. Feher J: Contribution of neurogenic inflammation to irritable eye syndrome. Adv Exp Med Biol 506: 1047-1050, 2002.

48. Baudouin C: A new approach for better comprehension of diseases of the ocular surface. J Fr Ophtalmol 30: 239-246, 2007 (In French).

49. Brecha NC, Sternini C, Anderson K and Krause JE: Expression and cellular localization of substance $\mathrm{P} /$ neurokinin $\mathrm{A}$ and neurokinin B mRNAs in the rat retina. Vis Neurosci 3: 527-535, 1989.

50. Caruso DM, Owczarzak MT and Pourcho RG: Colocalization of substance P and GABA in retinal ganglion cells: a computerassisted visualization. Vis Neurosci 5: 389-394, 1990.

51. Bagnoli P, Dal Monte M and Casini G: Expression of neuropeptides and their receptors in the developing retina of mammals. Histol Histopathol 18: 1219-1242, 2003.

52. May A, Shepheard SL, Knorr M, Effert R, Wessing A, Hargreaves RJ, Goadsby PJ and Diener HC: Retinal plasma extravasation in animals but not in humans: implications for the pathophysiology of migraine. Brain 121: 1231-1237, 1998.

53. Gaspar MN, Ribeiro CA, Cunha-Vaz JG and Macedo TR: Effects of neuropeptides on the sumatriptan-disturbed circulation in the optic nerve head of rabbits. Pharmacology 70 $152-159,2004$.

54. Nucci C, Gasperi V, Tartaglione R, Cerulli A, Terrinoni A, Bari M, De Simone C, Agrò AF, Morrone LA, Corasaniti MT, Bagetta $\mathrm{G}$ and Maccarrone M: Involvement of the endocannabinoid system in retinal damage after high intraocular pressure-induced ischemia in rats. Invest Ophthalmol Vis Sci 48 2997-3004, 2007.

55. Bronzetti E, Artico M, Kovacs I, Felici LM, Magliulo G Vignone D, D'Ambrosio A, Forte F, Di Liddo R and Feher J: Expression of neurotransmitters and neurotrophins in neurogenic inflammation of the rat retina. Eur J Histochem 51: 251-260, 2007.

56. Szolcsanyi J: Forty years in capsaicin research for sensory pharmacology and physiology. Neuropeptide 38: 377-384, 2004.

57. Fujita S, Shimizu T, Izumi K, Fukuda T, Sameshima M and Ohba N: Capsaicin-induced neuroparalytic keratitis-like corneal changes in the mouse. Exp Eye Res 38: 165-175, 1984

58. Ogilvy CS, Silverberg KR and Borges LF: Sprouting of corneal sensory fibers in rats treated at birth with capsaicin. Invest Ophthalmol Vis Sci 32: 112-121, 1991.

59. Gallar J, Pozo MA, Rebollo I and Belmonte C: Effects of capsaicin on corneal wound healing. Invest Ophthalmol Vis Sci 31: 1968-1974, 1990.

60. Waldrep JC and Crosson CE: Induction of keratouveitis by capsaicin. Curr Eye Res 7: 1173-1182, 1988.

61. Ritter S and Dinh TT: Capsaicin-induced neuronal degeneration in the brain and retina of preweanling rats. J Comp Neurol 296 447-461, 1990

62. Tombran-Tink J, Shivaram SM, Chader GJ, Johnson LV and Bok D: Expression, secretion, and age-related downregulation of pigment epithelium-derived factor, a serpin with neurotrophic activity. J Neurosci 15: 4992-5003, 1995.

63. Becerra SP, Palmer I, Kumar A, Steele F, Shiloach J, Notario V and Chader GJ: Overexpression of fetal human pigment epithelium-derived factor in Escherichia coli: a functionally active neurotrophic factor. J Biol Chem 268: 23148-23156, 1993.

64. Dawson DW, Volpert OV, Gillis P, Crawford SE, Xu H, Benedict W and Bouck NP: Pigment epithelium-derived factor: a potent inhibitor of angiogenesis. Science 285: 245-258, 1999.

65. Chung C, Doll JA, Stellmach VM, Gonzales J, Surapureddi S, Cornwell M, Reddy JK and Crawford SE: Pigment epitheliumderived factor is an angiogenesis and lipid regulator that activates peroxisome proliferator-activated receptor alpha. Adv Exp Med Biol 617: 591-597, 2008
66. Bouck N: PEDF: anti-angiogenic guardian of ocular function. Trends Mol Med 8: 330-334, 2002.

67. Spranger J, Osterhoff M, Reimann M, Mohlig M, Ristow M, Francis MK, Cristofalo V, Hammes HP, Shith G, Boulton M and Pfeiffer AF: Loss of the antiangiogenic pigment epitheliumderived factor in patients with angiogenic eye disease. Diabetes 50: 2641-2645, 2001

68. Zingsheim HP and Plattner H: Electron microscopic methods in membrane biology. In: Methods in Membrane Biology. Korn ED (ed). Plenum Press, New York, NY, pp1-146, 1976.

69. Hirai K, Aliev G, Nunomura A, Fujioka H, Russell RL, Atwood CS, Johnson AB, Kress Y, Vinters HV, Tabaton M, Shimohama S, Cash AD, Siedlak SL, Harris PL, Jones PK, Petersen RB, Perry G and Smith MA: Mitochondrial abnormalities in Alzheimer's disease. J Neurosci 21: 3017-3023, 2001.

70. Kelley DE, He J, Menshikova EV and Ritov VB: Dysfunction of mitochondria in human skeletal muscle in type 2 diabetes. Diabetes 51: 2944-2950, 2002.

71. Gosker HR, Wouters EFM, van der Vusse GJ and Schols AMWJ: Skeletal muscle dysfunction in chronic obstructive pulmonary disease and chronic heart failure: underlying mechanisms and therapy perspectives. Am J Clin Nutr 71: 1033-1047, 2000.

72. Ben-Shachar D: Mitochondrial dysfunction in schizophrenia: a possible linkage to dopamine. J Neurochem 83: 1241-1251, 2002.

73. Fox DA, Poblenz AT, He L, Harris JB and Medrano CJ: Pharmacological strategies to block rod photoreceptor apoptosis caused by calcium overload: a mechanistic target-site approach to neuroprotection. Eur J Ophthalmol 13 (Suppl 3): S44-S56, 2003.

74. Tyni T, Johnson M, Eaton S, Pourfarzam M, Andrews R and Turnbull DM: Mitochondrial fatty acid beta-oxidation in the retinal pigment epithelium. Pediatr Res 52: 595-600, 2002.

75. Andrews RM, Griffiths PG, Johnson MA and Turnbull DM: Histochemical localisation of mitochondrial enzyme activity in human optic nerve and retina. Br J Ophthalmol 83: 231-235, 1999.

76. Hiltunen JK and Qin Y: Beta-oxidation-strategies for the metabolism of a wide variety of acyl-CoA esters. Biochem Biophys Acta 1484: 117-128, 2000.

77. Kuksa V, Imanishi Y, Batten M, Palczewski K and Moise AR: Retinoid cycle in the vertebrate retina: experimental approaches and mechanisms of isomerization. Vision Res 43: 2959-2981, 2003.

78. Sparrow JR, Fishkin N, Zhou J, Cai B, Jang YP, Krane S, Itagaki $\mathrm{Y}$ and Nakanishi $\mathrm{K}$ : A2E, a byproduct of the visual cycle. Vision Res 43: 2983-2990, 2003.

79. Sprecher H: Metabolism of highly unsaturated n-3 and n-6 fatty acids. Biochim Biophys Acta 1486: 219-231, 2000.

80. Hettema EH and Tabak HF: Transport of fatty acids and metabolites across the peroxisomal membrane. Biochim Biophys Acta 1486: 18-27, 2000

81. Kliewer SA, Sundseth SS, Jones SA, Brown PJ, Wisely GB, Koble CS, Devchand P, Wahli W, Wilson TM, Lenhard JM and Lehmann JM: Fatty acids and eicosanoids regulate gene expression through direct interactions with peroxisome proliferator-activated receptors alpha and gamma. Proc Natl Acad Sci USA 94: 4318-4323, 1997.

82. Kersten S, Desvergne B and Wahli W: Roles of PPARs in health and disease. Nature 405: 421-424, 2000.

83. Nagy L, Tontonoz P, Alvarez JGA, Chen H and Evans RM: Oxidized LDL regulates macrophage gene expression through ligand activation of PPARgamma. Cell 93: 229-240, 1998.

84. Murata T, He S, Hangai M, Ishibashi T, Xi XP, Kim S, Hsueh WA, Ryan SJ, Law RE and Hinton DR: Peroxisome proliferator-activated receptor-gamma ligands inhibit choroidal neovascularization. Invest Ophthalmol Vis Sci 41: 2309-2317, 2000.

85. Forman BM, Chen J and Evans RM: Hypolipidemic drugs, polyunsaturated fatty acids, and eicosanoids are ligands for peroxisome proliferator-activated receptors alpha and delta. Proc Natl Acad Sci USA 94: 4312-4317, 1997.

86. Keller H, Dreyer C, Medin J, Mahfoudi A, Ozato K and Wahli W: Fatty acids and retinoids control lipid metabolism through activation of peroxisome proliferator-activated receptorretinoid X receptor heterodimers. Proc Natl Acad Sci USA 90: 2160-2164, 1993.

87. Brunk UT and Terman A: The mitochondrial-lysosomal axis theory of aging: accumulation of damaged mitochondria as a result of imperfect autophagocytosis. Eur J Biochem 269: 1996-2002, 2002. 
88. Katz ML, Rice LM and Gao CL: Reversible accumulation of lipofuscin-like inclusions in the retinal pigment epithelium. Invest Ophthalmol Vis Sci 40: 175-181, 1999.

89. Von Ruckmann A, Schmidt KG, Fitzke FW, Bird AC and Jacobi KW: Dynamics of accumulation and degradation of lipofuscin in retinal pigment epithelium in senile macular degeneration. Klin Monbl Augenheilkd 213: 32-37, 1998 (In German).

90. Kennedy CJ, Rakoczy PE and Constable IJ: Lipofuscin of the retinal pigment epithelium: a review. Eye (Lond) 9: 763-771, 1995.

91. Marmorstein AD, Marmorstein LY, Sakaguchi H and Hollyfield JG: Spectral profiling of autofluorescence associated with lipofuscin, Bruch's membrane, and sub-RPE deposits in normal and AMD eyes. Invest Ophthalmol Vis Sci 43: 2435-2441, 2002.

92. Feher J, Kovacs I, Artico M, Cavallotti C, Papale A and Balacco Gabrieli C: Mitochondrial aterations of retinal pigment epithelium in age-related macular degeneration. Neurobiol Aging 27: 983-993, 2006.

93. Furuno T, Kanno T, Arita K, Asami M, Utsumi T, Doi Y, Inoue $\mathrm{M}$ and Utsumi $\mathrm{K}$ : Roles of long chain fatty acids and carnitine in mitochondrial membrane permeability transition. Biochem Pharmacol 62: 1037-1046, 2001.

94. Pepe S: Mitochondrial function in ischaemia and reperfusion of the ageing heart. Clin Exp Pharmacol Physiol 27: 745-750, 2000.

95. Gunthorpe MJ and Szallasi A: Peripheral TRPV1 receptors as targets for drug development: new molecules and mechanisms. Curr Pharm Des 14: 32-41, 2008.
96. Lázár J, Szabó T, Marincsák R, Kovács L, Blumberg PM and Bíró T: Sensitization of recombinant vanilloid receptor-1 by various neurotrophic factors. Life Sci 75: 153-163, 2004.

97. Aloe L, Tirassa P and Lambiase A: The topical application of nerve growth factor as a pharmacological tool for human corneal and skin ulcers. Pharmacol Res 57: 253-258, 2008.

98. Feher J, Kovacs I, Pacella E, Keresz S, Spagnardi N and Balacco Gabrieli C: Pigment epithelium-derived factor (PEDF) attenuated capsaicin-induced neurotrophic keratouveitis. Invest Ophthalmol Vis Sci 50: 5173-5180, 2009.

99. Gao G, Li Y, Zhang D, Gee S, Crosson C and Ma J: Unbalanced expression of VEGF and PEDF in ischemia-induced retinal neovascularization. FEBS Lett 489: 270-276, 2001.

100. Jin KL, Mao XO and Greenberg DA: Vascular endothelial growth factor: direct neuroprotective effect in in vitro ischemia. Proc Natl Acad Sci USA 97: 10242-10247, 2000.

101.Zachary I: Neuroprotective role of vascular endothelial growth factor: signalling mechanisms, biological function, and therapeutic potential. Neurosignals 14: 207-221, 2005.

102. Khaibullina AA, Rosenstein JM and Krum JM: Vascular endothelial growth factor promotes neurite maturation in primary CNS neuronal cultures. Brain Res Dev Brain Res 148: 59-68, 2004

103. Feher J, Papale A, Mannino G, Gualdi G and Balacco Gabrieli C: Mitotropic compounds for the treatment of age-related macular degeneration. The metabolic approach and a pilot study. Ophthalmologica 217: 351-357, 2003. 